\title{
'Disappearing Women': A Study of Women Who Left the UK ICT Sector
}

\author{
Marie Griffiths', Karenza Moore ${ }^{2}$
}

\begin{abstract}
Women continue to leave the UK ICT sector in disproportionate numbers, yet little research has documented this phenomenon. In contrast, the majority of existing studies in this area concentrate on women who remain in the ICT workplace. The 'Disappearing Women: Northwest ICT project reported in this paper focused on women who left the UK ICT sector and allowed their voices to be heard, telling how they had been overlooked and effectively silenced. Drawing on nine in-depth qualitative autobiographical interviews, we identify a typology of 'disappearing women' from the ICT sector and several reasons for their decision to do so. The relevance of these findings for policy and practice is also discussed.
\end{abstract}

Keywords: gender; ICT workplace; UK ICT sector; autobiographical interviews; co-produced interviews, women and IT.

\footnotetext{
' ISOS Research Centre, University of Salford, The Crescent, Salford, M5 4WT, UK, 0161 2955. Email: m.Griffiths@salford.ac.uk

2 Department of Applied Social Sciences, Bowland North, Lancaster University, LAI 4YT, UK, 0152493570.

Email: karenza.moore@lancaster.ac.uk
} 


\section{Introduction}

This paper reports and analyses the findings of the 'Disappearing Women: Northwest ICT' project, which was one of several gender projects undertaken by the University of Salford, $\mathrm{UK}^{3}$ to further understand why more women leave the sector than are being recruited. Whilst speaking to women working in the ICT sector, it became apparent to the research team that many of their colleagues who had left the sector had been pushed out or left due to a dissatisfaction with their work situations. This specific cohort of 'disappearing women' has been subject to little (if any) research so far. Overall, our qualitative study aims to continue the debate on the attrition of women from the sector by speaking directly to those that have left, attempting to understand the broader picture in the UK IT workforce (Platman and Taylor, 2004). The project was based on the assumption that 'disappearing women', once found, may be able to facilitate a more in-depth understanding of why women leave the ICT sector.

Women's 'disappearance' from the ICT sector is documented by significant evidence from the literature. For example, the Department of Trade and Industry (DTI, 2003) shows that $36 \%$ of new ICT recruits in the UK in the first quarter of 2002 were women, yet in the same period, women accounted for $46 \%$ of all leavers or 'disappearing' women. The drop from $27 \%$ of women making up the ICT workforce in 1997 to $21 \%$ in 2004 suggests a continually declining trend (DTI, 2004). The number of women in the ICT sector remains disappointingly small, considering that women make up around $50 \%$ of the total UK workforce. Moreover, this figure has gradually continued to fall despite numerous initiatives to attract more women into the sector (see Griffiths and Moore 2006 for a list of high profile 'women in ICT' initiatives). The 'disappearing' women, for whatever reasons, decided to leave the sector and change their career trajectories, in spite of having amassed skills and expertise, qualifications in ICT and crossed ICT recruitment barriers (DTI, 2005a). What 'chilly' workplaces (Faulkner, 2004),

3 The DW: NW ICT project was partly funded by the European Social Fund (ESF) from April 2006 until December 2006 under ESF Objective 3, Policy Field 5.I: Improving the Participation of Women. The DW: NW ICT project contributes research to priority 5 and its strategic objective to reduce the level of disadvantage faced by women in the labour market. The project was run in the Information Systems Organisation and Society (ISOS), Salford Business School, University of Salford, Greater Manchester, UK. disinterested organisational cultures and indifferent working conditions had these women encountered that became determining factors in their leaving the ICT sector?

The paper is structured as follows. The first section presents the backdrop for the research, looking at women in the ICT labour market in England in general, and then women leaving the ICT sector. The methodology follows, explaining the approach adopted to locate this 'hard to reach' target sample, the autobiographical interview process and procedures adopted. The findings described in the next section provide the reader with the opportunity to hear the voices of the 'disappearing' women, highlighting a typology of 'disappearing' women from the ICT sector and several reasons for departure. Our findings echo Panteli et al.'s (1999) concerns that there is little evidence that organisational culture is changing, regardless of any 'family-friendly' legislation. Furthermore, we found that gender issues in the workplace were not viewed as significant, but rather a hindrance in getting the job done this, coupled with a lack of visible role models, made for hostile environments for the women in our study. The Conclusions emerging from this body of research, which are described in the last section of the paper, contribute to informing practitioners, governments and policy makers across Europe about ways to improve the participation of women in the ICT sector.

\section{Research background: Women 8 orking in ICT}

Employment in the ICT sector has continued to grow significantly in recent years, but this growth has not led to a parallel increase in women's presence in the ICT labour market. Current research shows that there is a problem not only in attracting women into the sector, but also in retaining them (Adam et al.., 2006). The workforce is predicted to grow between $1.5 \%$ and $2.3 \%$ per annum throughout the next decade, which, in real terms, means an estimated additional 179,000 IT professionals to join the workforce over the next ten years (e-skills, Nov 2004). However buoyant the sector is becoming, evidence indicates that women remain severely under-represented in the ICT profession in the UK (Trauth et al., 2004). As Juliet Webster (2005) states, "IT professionals are typically male, young (in their mid twenties), and without domestic responsibilities" (2005:2). 
Reviewing the current and predicted workforce, Stone (2003) reinforces Webster in her observation: "you don't need just pale, male and stale guys in the boardroom, but a diversity of views". In comparison to the general increasing growth of the sector, women's employment figures are in decline, despite twenty years of continuous efforts and concerns of policy makers and gender equality practitioners (Webster 2005). Indeed, the effect of decades of equal opportunity and related policies, many government initiatives designed to address the gender imbalance in ICT employment patterns, sex segregation in ICT occupations and gender pay gap in the ICT sector, on the position and number of women in the ICT workforce remains minimal. Richardson and French (2005) argue that these initiatives can be interpreted as a means to fill the skills gap and 'make up the numbers' to shore up the UK economy, resulting in 'an add-more-women-and-stir' solution to the 'problem' rather than attempting to understand why it happens (Henwood, 1996).

Platman and Taylor (2004) report a drop from a high point of 100,892 women in the UK IT workforce in 1999, to 53,759 by 2003 . Moreover, although women are making inroads into technical and senior professions, there remains a 'feminisation' of lower level jobs, with a female majority in operator and clerical roles and a female minority in technical and managerial roles (Griffiths et al., 2005). For example, in the UK, Office of National Statistics (ONS) statistics indicate that women accounted for $30 \%$ of IT operations technicians, but a mere $15 \%$ of ICT managers and only II\% of IT strategy and planning professionals (EOC, 2004). Again, this is a classic case of vertical gender segregation, with women more strongly represented in lower level ICT occupations than in higher status and higher paid arenas (EOC, 2004a).

\section{Methodology}

The 'Disappearing Women: Northwest ICT' (DW: NI) project, which ran from April 2006 until December 2006, aimed to further understand why more women leave the UK ICT sector than are being recruited. The research approach of this project was steered by our earlier study 'Women in Information Technology' (WINIT), which ran for two years, from January 2004 until March 2006 at the University of Salford's Information Systems Institute, with partial funding by the European Social Fund (ESF). This project dealt solely with women who worked in ICT in non-ICT organisations in England, and women who have left ICT in the North West of England. Using an online questionnaire and indepth interviews, the WINIT project gathered the stories and experiences of up to 479 participants and 19 interviewees respectively.

In the DW: NI project, the key data collection method was a series of nine in-depth qualitative autobiographical interviews, conducted with women at different points in their lives and careers. All the women had previously worked in the ICT sector in the North-west of England at the time of the interviews. There were no universal worklife history patterns with the women leaving the ICT sector, 'disappearing' at diverse stages in their career and for a variety reasons. Given that the women who participated in this study were self-selected, they were also heterogeneous in terms of age (25-30 years old to 60-65 years old), which reflected a wide range of ICT career stages - exploring/starting out, establishing/progressing and reflecting/retiring (Moore et al., 2006), a variety of job roles (a Help Desk team leader through to a Vice President) and a range of ICT organisational responsibility, pay and rewards. Only three out of the nine women had children with seven out of the nine being in a relationship.

The autobiographical interview was regarded as a momentary social relationship and meaning-making occasion (Jarvinen, 2000), during which interactions between the interviewer and interviewee construct past events to make sense of present positions and future directions (Moore et al. 2006). We also took into account Wagner and Wodak's view (2006) that the autobiographical interviews are constructed from the interviewee's present social position and life position, which colour the interview together with the interview process itself. We explored what was perceived as 'significant events' in relation to the process of leaving ICT. During the interview process, women were able to express their disbelief at the way in which they had been treated within the ICT workplace, whilst constructing a current, more self-aware persona through their depictions of the leaving process. For many of our research participants, the sometimes emotional interviews offered a space where their own 'personal journey' was considered within the broader socio-political context.

Prior to the interviews, the women were effectively asked to reflect upon their ICT careers. We suggested them to 
recall their work-life events in a chronological manner, usually starting from their educational background to the present day. Such a structured process gives meaning to both the interviewee and the listener. Comments were often made that this was the first time in years or ever that they had 'returned' to what had been distressing episodes in their life. Throughout the interview process, certain events were probed and then explored in more detail and in some instances the women were encouraged to elaborate more on key events. This could be described as objective research in some ways, but the actuality was that time was often a limiter; the 'disappearing' women wanted to tell their experiences of the ICT work place in some cases voicing their opinions for the first time. As researchers, we were aware that in recalling painful periods of their lives, some women found this emotional.

By shifting the research lens upon those women in ICT that have left rather than those who remained, we anticipated that they may offer a more definitive insight into working practices in the ICT sector. This 'shift' posed several problems in the research process, given that the research team perceived this sample group as particularly "hard to reach' (Atlinson and Flint, 200I). These women were and are scattered across a myriad of workplaces, industry sectors and they stand outside school gates, there are no clusters of ex-female ICT workers on forums, or in networks to initially target. Drawing on the resulting sample of nine former female ICT professionals, the stories we present reflect a broad spectrum of career backgrounds, unique family units and life experiences.

The interviews were transcribed, so both audio and text were included in the analysis process of drawing together data. The analysis of the transcripts relied on the identification of key words and phrases.

Our findings are organized in two main categories, described in detail in the next section:

I. Reasons for departure, such as heavy workload and long hours, ostracizing and hostilities in the workplace, 'turning points' in life, ageism, illness/disability, dual roles, and a 'realisation' that they did not have to stay.

2. A typology of 'disappearing' women from the ICT sector. Vignettes of the nine women were also constructed to offer the reader an insight into the personal lives of our interviewees on both a domestic and working level (see Appendix I: Vignettes of the Disappearing Women).

\section{Findings:}

\section{a. Reasons for Departure}

\section{Heavy Workload and Long Hours}

"It was long hours, it was weekends. You would get called out in the night, you know that whole thing but I didn't have any kids and I enjoyed doing the work. I liked the problem solving."

In spite of the assumption that typically ICT work does not impose strict spatial and temporal demands on the workforce as other traditional roles, including through enabling mobile technologies and virtual workplaces, our interviews revealed that there is still a long hour culture and presenteeism to contend with (Griffiths et al. 2006; DTI, 2005a). This resonates with Edwards and Wacjman (2005), who highlight observable changes experienced by the workforce, increased working hours and workloads with UK employees working harder than ever before, and call for an adjustment of both the character of the typical worker and workplace.

All the women in our sample reported a lack of job satisfaction, a continuous struggle to maintain a family/work/life balance due to long periods at work and a burgeoning workload. Others reported long hours associated with travel. For example, Lydia a specialist trainer of bespoke systems remembers: "there would be hours when you know if I had to go off and do training and I went to the Birmingham site, it is about setting off to get there for nine. ... But for me that would mean me setting off at five to get back at six". Although she negotiated extra expenses, she still had to spend more time away from her family: "I said:' I am not doing that any more, I'm setting off on a Sunday and you can pay for the hotel', which made it better for me, but you are leaving here (home) at six o'clock (on the Sunday evening), it meant even more hours away from home".

Belinda stayed with her company for 13 years and struggled to switch off from what had been a hectic schedule over this time: "going to London two or three times a week, catching the 5.15 (am) train, back at 9.30 (pm), being in work the next day". She also added that: "if you wanted to get on and be well 
thought of, you put in the extra hours. I quite often worked Saturday mornings, Sunday afternoons - I would be travelling Sunday night to be somewhere Monday morning...twelve hour days, I always tried to be home about $7 \mathrm{pm}$ " she recalls, though not negatively: "you really did not have a life outside the office". Belinda enjoyed her status and accepted that working such long hours was necessary to progress.

\section{Ostracising and Hostilities}

"I was almost like a square peg- I was still the only technical woman in the department."

All the interviewed women spoke of being excluded or ostracised in some way within the workplace - an aspect that is well known as bullying and harassment at work. Hostilities took on many forms:

(i) Overt: "Well, I'm not big on cleavage anyway, but there was a lot of playful talk about my chest all the time, so I always dress, you know, covered up";

(ii) Covert: "I came back (after maternity leave) and there was no desk for me... well, it felt kind of difficult, really, but, you know, it wasn't entirely surprising";

(iii) Discriminatory: "We used to have a weekly meeting in his (the director's) office and he used to make sexist jokes and I would just say to him that I don't find him funny. So I wasn't his sort of girl really, I didn't flirt with him. You know, I wasn't his thing";

(iv) Slanderous: "Yes, that helped a lot, although inevitably you get the all the stuff about, you must be having an affair...you can't go for lunch with anybody in your team ...everybody in your team is male, so you either go with a male or you go on your own". It appears that women are still undervalued in the ICT sector and that a loutish behaviour is tolerated in some ICT organisations. How do female ICT professionals respond to this 'chilly' ICT workplace culture where such sexist stereotypes continue? One woman poignantly says: "It can be dangerous and it can be undermining, and sometimes I think it might determine your position".

\section{'Turning Points' in Life}

"You need to let go of all that history, and that time I needed to, because it's like when you are turning a corner, the first bit of turning the corner you are still looking behind at where you have come from, and then there is a point when you go around the corner, where you can't see behind, you can only see ahead"

'Turning points' have been described by the intervieweed women as an episode in their life history that either was the last straw or allowed time for reflection. Generally, the women portrayed these 'turning points' as a negative specific occurrence, such as illness, geographical relocation, being undermined, being forced to work overseas despite immediate childcare responsibilities, and being unable to return to the industry following redundancy, etc., with a positive outcome. Although such occurrences 'disrupted' the linear 'flow' of their life history, the 'disruption' allowed for reconsideration, often undertaken with family, friends, and former and new colleagues, of their work/life goals and core personal values.

\section{Ageism}

"I suppose it was a combination of age and being $a$ woman"

The term ageism was coined in the 1960's, defining a process of discrimination and stereotyping against people just because of chronological age. Ageism views all older people as the same, regardless of their different life trajectories and has implications with regard to discrimination at work, loss of status, stereotyping and dehumanisation. Research on older workers has been largely gender specific, focusing in particular on older men's exit from the workforce (Ainsworth, 2002), but there has been a tendency to 'turn a blind eye' in relation of ageism against women workers especially in the ICT sector. As recently as 2009, the Australian Computer Society's Women's Board (ACS-W) surveyed 2,400 female members to understand the persistent high levels of attrition in the sector and ageism. 26\% (624 women) of the survey respondents were women over 50 years of age and they reported that not only did they feel discriminated against because of their gender, but also because of their age (Bandias and Warne, 2009). Griffiths et al. (2006) looked at the various challenges that women faced working in the ICT sector in relation to the age, their life stage and the career stage arguing that women of different ages may progress through their careers at different rates depending upon various factors often unique to women, such as 
expectations of women to be primary carers and to juggle this dual role.

Our interviews suggested that age cannot be isolated as just one problem women face in ICT, but contributes overall to their stressful situation.

\section{IIIness/Disability}

Of the nine women who contributed to this research, three experienced periods of illness and/or disability leading to sick leave. Cleo suffered two miscarriages: "He (her son) was born in '99 and in the meantime I had two miscarriages, which I think were stress-related, because I was under a lot of pressure at that point. I took a lot of time off with the second one, because I was a wreck". Chrissie placed responsibility of a serious road accident on to her employer because of intense work-load and stress.

The experiences of the women we interviewed in this research revealed the ICT sector's long hour ethos, higher job demands, 'chilly' workplace culture (Faulkner, 2004), and lack of take-up of work-life balance initiatives (DTI, 2004, Kodz, 2002) which contributed to high levels of stress. Stress levels are amplified even further by managing multiple roles (e.g. parent and IT professional) and decreased psychological well-being. Stress possibly contributed to their weakened emotional well-being and increased sickness absence. There has been increased awareness and legislation for family-friendly schemes and the provision of work-life balance initiatives for those with dependant responsibilities. Conversely, more attention is being paid to encourage organisations to include those employees that do not necessarily have dependents (Bond 2004). Research suggests that the greatest impact on work-life balance is organisational culture rather than laws or policies (Bond 2004). However, without the foundation of a supportive organisational culture to build upon, any work-life balance initiatives become "empty shells: they contain nothing of substance or value" (Hogue and Noon 2004:482), and the family-friendly schemes continue to depend upon the attitudes of the individual line manager, as illustrated by the experiences of women in our study.

\section{Dual Roles}

"The problem, from my point of view, is when I got back into a technical role. If there was a crisis at 4 o'clock when I was leaving, I was stuck. And from my point of view, that was additional stress for me. It was the role I wanted to do, it was the front line support stuff that I really liked doing, but it didn't really work with what I was trying to do with the family."

We have included this section to highlight a subtle distinction regarding women who want to pursue a fulltime career and be at work rather than at home: "Well, I still did (work long hours and weekends), I went full time with (my daughter), I used to go in very early in the morning, my partner would drop her at nursery and I went in and did what I was doing before... And I was keen to go back to work, although she was a very unhappy baby, it was a bit grim really being at home." Others spoke honestly about their situations: "No, I definitely wanted to get back and it felt like real freedom to get back to work".

However, once these women return to work full-time, the reality is different. The issues of managing a work-life balance threads throughout this report, but perceptions alter when women professionals become mothers at an organisational and personal level. Despite wanting to maintain her career in ICT, one woman was impeded: "Once I took maternity leave (and in my view that was when the rot set in), I didn't have another promotion after Lisa was born".

Women's endeavour to manage domestic and work duties is seen by Hennig and Jardim (1977:17) as "living two lives", unlike men, who are more able to separate career and personal goals, trading one off for the other to maintain equilibrium, but women struggle to make that distinction. Furthermore, attempting to detach the two (domestic and work) encourages a personal conflict in how that the distinction is negotiated and maintained (ibid).

Gill, reporting on her observations of her female colleagues, adds to the flavour of how challenging it is to want to work, but also want to be mother. We are given an insight into the pressure 'Amy' is under to be seen to perform, regardless of just having her baby.

"The image I have is in a New York hotel room, this woman Amy, who had given birth a month or so before expressing her own breast milk in the hotel bathroom and I'm just thinking that's wrong. She should be with her baby or there are so many ways you can work now from home, that it should now be more women friendly. And I could see the whole pressure on Amy that she didn't want to, she felt that if she didn't go to this meeting in New York that she'd loose

ISSN: 07 I 8-2724. (http://www.jotmi.org)

Journal of Technology Management \& Innovation (C) Universidad Alberto Hurtado, Facultad de Economía y Negocios 
out, somehow she would lose the momentum of the job, she didn't want to be a stay-at- home mum, but she was desperately torn about leaving her baby, desperately and it was utterly painful to watch."

\section{A 'Realization' that They did Not Have to Stay}

"I don't mind doing the hard work, but where the hard work is purely down to the money and the money goes into somebody else's pocket, not necessarily for a good, and I wasn't sure what good it was, but it wasn't the company."

Some of our women gradually realised that they were surrounded by individuals that had very different values: "people had values like they wanted the next BMW...it was all very status conscious". One of the women questioned her motivation to leave the ICT sector: "my move out of IT was not for that, it was really, although I didn't get it at the time, it was because I didn't find it meaningful." Another woman echoes the word 'meaningful' regarding her perception of what working in the industry meant to her: "typing data into a machine, what's it for? It's not meaningful." Lydia began to look at what working for a private organisation actually meant and realised it was not contributing to society on the whole. Disillusionment regarding her career was beginning to overwhelm her and she was finding it hard to justify her position at work and her role in society:

"I didn't want to work for somebody who... I don't mind doing the hard work, but where the hard work is purely down to the money and the money goes into somebody else's pocket, not necessarily for a good, and I wasn't sure what good it was. I'm sure I didn't want to work for a private company again. People slogging their guts out, people sleeping in cars, people working eighteen, twenty odd hours because somebody wants to make a bit more money and I don't agree with it. But my experience of a private company, especially when you are in to marketing as well, so I just didn't want to do that, I wanted to work for a non-for-profit, work for a charity or do something that l'd like. Also because I knew that with the skills that I had I could really help somebody".

\section{b. A Typology of Women Leaving the ICT Sector}

Despite the heterogeneity of reasons for departure discussed above, a number of shared experiences were reported, based on which we realized that the overall category of 'disappearing' women actually encompasses four different sub-categories (see Table I: A typology of 'disappearing' women from ICT sector, for an overview of which category the women in this study fell into):

(i) 'Potential returners': women who left the sector often after a career break taken to start a family or to care for an elderly or disabled relative, and attempt to return to work (but haven't done it yet).

(ii) 'Discarded': women who attempted to get back into the sector, but have faced restricted opportunities and barriers such as age, disadvantaging recruitment processes and regional economic disparities. These women have been unable to get back in to the ICT sector and have been forced to find employment elsewhere or take early retirement.

(iii) 'Alienated': have left the sector for wide-ranging reasons, vowing never to return, in contrast to the 'potential returners' or the 'discarded' categories above.

(iv) 'Re-appearing' (Where I moved next): a high proportion of the 'discarded' and 'alienated' women embarked upon a radical shift away from a technical, intensive, dynamic and often authoritative work life. It is very interesting that in choosing a new career, almost all of the're-appearing' women gravitated towards caring occupations that dealt primarily with people. Either through choice or circumstance, the women orientated towards caring, listening occupations, with a face-to-face mode of working. Our study only draws upon nine women's experiences, and we can only report on findings from this study, so it would be inappropriate to make a generalization that all women who leave the sector move to caring professions. However, this was an unexpected finding that provides significant evidence to support future research for an extended study of this phenomenon. The interviews transcripts reveal that the women reported an overriding sense of dehumanization occurring within their ICT workplaces. This suggests that changes either in their job roles or in the industry were slowly eroding their individuality and/or removing certain altruistic characteristics that they once had or previously viewed as key motivators for an ICT career. 


\section{I. 'Potential returners':}

Lydia: found juggling her personal and work life more and more stressful, resulting in her finally succumbing to the pressure. She took a six month career break but hasn't returned to ICT yet.

Maddy: is a disillusioned unemployed woman in her mid-twenties, whose ICT career path was 'cut short' due to relocating to the North West of England.

\section{2. 'Discarded women':}

Beatrice: is a competent $60-65$ year old, married with no children. She has worked in the ICT industry all her working life and was eventually 'pushed out' through redundancy.

Carla: describes the shift from ICT as a positive diversion in her career trajectory even though she never intended to 'disappear' from the industry planning to work in ICT until retirement age, but was forced out by redundancy.

\section{3. 'Alienated women':}

Belinda: is a restless $40-45$ year old single woman. The higher she climbed the corporate ladder, the opportunities reduced and she believed "there was a plateau with lots of others at my level with limited access to the board level".

Dee: is presently working contently as a self employed bereavement counselor. She had found something more "meaningful and satisfying...it's lives and people that matter", but it had taken the experience of losing a child to realise this.

Cleo: is a perceptive 40-45 year-old married mother of two, who acknowledged that becoming a mother had altered others' perceptions of her. The organisation suddenly became 'chilly'.

Chrissie: is a focused 30-35 year old married mother of two, who found it increasingly more difficult to 'juggle' a work life.

Gill: is a single, self-motivated, confident $45-50$ year old, who is currently enjoying life working as a self-employed health therapist after disappearing from the ICT sector.

\section{4. 'Re-appearing Women ${ }^{4}$ :}

Dee: as a bereavement counselor, she thought that her main priority was to work with people, regardless of what job role enabled her to achieve this: "How I moved into counseling?... when he (her son) is in school full time, I could then hopefully be ready to go back to something, but it's that thinking, what do I do? And I knew I like people, I wanted to work with people, I was already thinking counseling, along that kind of line... and I thought, well, I've been through a rough experience myself'.

Gill: is now a successful and recognised health practitioner "... and that was nearly six years ago and I have established a very successful practice. And it's not just hypnotherapy, it's gone beyond that. I call what I do 'emotional health"'.

Cleo: retrained for three-years and is now a nutritionist with an established practice. Recently she has formed a partnership with another therapist offering a complementary service with future plans for expansion.

Maddy: was on the threshold of committing herself to further training and fees;

Chrissie: took up a teaching career.

Table I. A typology of 'disappearing' women from the ICT sector.

\footnotetext{
${ }^{4}$ Given that Beatrice, Lydia and Belinda have not yet 'appeared' in new professions, not all of our autobiographical accounts have been conclusive. Both Beatrice and Maddy became 'disappearing' women by default, as they could not get back in to the sector due to ageism along with other discriminating recruitment barriers. Belinda is still casually searching, tentatively 'dipping her toes' into new sectors and job roles with no real sense of urgency. Lydia is also searching, but with determination, employing the services of a life-coach as she has high aspirations of finding the right job in the right sector.
}

ISSN: 07/8-2724. (http://www.jotmi.org)

Journal of Technology Management \& Innovation (C) Universidad Alberto Hurtado, Facultad de Economía y Negocios 


\section{Conclusion}

This study analyses the ongoing and escalating issue of women leaving the ICT sector. Reasons why our 'disappearing women' did not want to stay in ICT or could not get back into ICT, included workload and long hours, ostracizing and hostilities, ageism, dual roles and/or relocation. The self-selective sample of 'disappearing women' is a heterogeneous one that represents many different types of women at different life-stages, but with shared experiences of hostile ICT workplaces. We identified four basic types of 'disappearing women: 'potential returners, 'discarded', 'alienated' and'reappearing'. Their post-IT career paths included in almost all cases caring occupations that dealt primarily with people. Either through choice or circumstance, the women orientated towards caring, listening occupations, with a face-to-face mode of working: one became a nutritionist, another a bereavement counselor, while yet others turned to hypnotherapy, two moved into education, and one women aims to become a life-coach. This leaves one woman who has retired, and two women who have yet 'moved on' to an alternative career.

We caution policy makers that it is not enough just to devise strategies to increase women into ICT workplaces; organisational culture needs to change too, so that women who are in the workplace remain there, managing diversity needs to be firmly established on organisational agenda. Policy-makers and decision makers within organizations should be familiar with this heterogeneous workforce and aim to introduce flexible policies that capture such diverse needs. It is not enough to simple propose recommendations, but strategies needs to be in place to practically apply and raise awareness of these diversity policies, then monitor and measure the outcomes. The work conducted by Kodz et al. (2002) tagged the 'take-up' gap phenomenon they observed in workplaces. They found that work-life balance initiatives, flexible work and part-time work were deemed as 'career suicide' by individuals, or were viewed by managers as a lack of commitment. In addition, some workers argued their heavy workload prevented them 'taking up' these opportunities.

This suggests that organisational cultural changes are critical to any diversity policies or work-life balance initiatives that maybe introduced. The 'take-up' gaps identified by Kodz et al. (2002), and the reasons for leaving given by our 'disappearing women' can only be addressed though cultural changes in the workplace. It is well documented that the gender and ICT academic community have raised their concerns on this matter over the past decades, e.g. Panteli et al. in 1999 and Queensberry in 2006 added to the debate.

We acknowledge there has been some progress in familyfriendly legislation over the past decade. Future planned legislation may soon be giving practitioners and decisionmakers a gentle push start. The Equality Act 2010 (that will come into force in October 2010), introduces a single legal framework to provide a streamlined law that aims to be more effective at tackling disadvantage and discrimination in and out of the workplace (http://www.equalityhumanrights.com). Interestingly for the purposes of this study, the legislation includes provisions for outlawing age discrimination, tackling the gender pay gap, promoting equality through procurement, clarifying aspects of discrimination law and positive action. The authors of this study applaud and endorse this new law. By highlighting recent stories of discrimination in the ICT workplace, they hope that this will spotlight the sector and challenge those in senior positions to introduce these measures. This is because we find that a toxic ICT work environment for women persists.

We recognise the limitations of our empirical research, given that the main body of research is drawn from a sample of nine autobiographical interviews, so a generalization of our findings needs to be investigated though further research to include a wider cohort.

\section{Acknowledgements}

Firstly, we would like to thank Professor Alison Adam and Dr Helen Richardson - the Disappearing Women: North West ICT project directors, and Beryl Burns, who also worked on the project. Finally, we would like to recognise the European Social Fund (ESF) who partly funded this study. I would also like to thank Dr. Marina Ranga for all her help in the review process of this paper.

\section{References}

ADAM, A., Griffiths, M., Keogh, C., Moore, K., Richardson, H., Tattersall, A. (2006 in preparation). Being an IT in IT: 
Gendered Identities in the IT Workplace. European Journal of Information Systems (EJIS): Special Issue on Organisational and Ethical Issues in the Information Society, 15, 368-378

AINSWORTH, A. (2002). The 'Feminine Advantage': A Discursive Analysis of Invisibility Of Older Women Workers. Gender, Work and Organisation, 9(5).

BANDIAS, S., Warne, L. (2009). 'Women in ICT - Retain and Sustain: An Overview of the ACS-W Survey'. 20th Australasian Conference on Information Systems, 2-4 Dec 2009, Melbourne

BOND, S. (2004). Organisational Culture and Work-life Conflict in the UK. International Journal of Sociology and Social Policy, 24(I2)

DTI (2004). 'Flexible working in the IT Industry: Long hour cultures and work-life balance at the margins?' http://www.dti.gov.uk/industries/electronics/flexworkit04.pdf.

DTI (2005a). Women in the IT Industry: Towards a business case for diversity. DTI, London.

DTI (2005b). Women in the IT Industry: Phase 2 Research How to retain women in the IT industry. DTI, London.

EDWARDS, P., Wajcman, J. (2005) The Politics of Working Life. University Press, Oxford.

EQUAL OPPORTUNITIES COMMISSION (EOC, 2004), Occupational Segregation, gender gaps and skills gaps, Occupational Segregation. Working Paper Series No.I5.

E-SKILLS (2005). IT Insights: Regional Skills in the North West, London.

E-SKILLS (2006). Women in IT (www.e-skills.com/women)

FAULKNER, W. (2004). Strategies of Inclusion: Gender and the Information Society. University of Edinburgh, European Commission IST Programme.

DTI (2003). Achieving Workforce Diversity in the E-Business on Demand Era, IBM/Women in IT Champions/George, R. http://www.intellectuk.org/sectors/it/women_it/2003/Achie vingworkforcediversity.pdf [accessed August 2004]
GRIFFITHS, M. Moore, K. (2006). The Women in IT (WINIT) Final Report, University of Salford, Greater Manchester

GRIFFITHS, M, Keogh, C., Moore, K., Richardson, H., Tattersall, A. (2006). Inclusion through the ages? Gender, ICT workplaces and lifestage experiences'. In: Kendall, J., Howcroft, D., Trauth, E., Butler, T., Fitzgerald, B and DeGross J.I. (eds) 'Social inclusion: societal and organisational implications for information systems' Springer-Verger IFIP WG 8.2 conference on Social Inclusion. Limerick July 2006

HENNIG, M., Jardim, A. (1977). The Managerial Women. Anchor Press/Doubleday, Garden City, NY.

HOGUE, K., Noon, M, (2004). Equal Opportunities policy and practice in Britain: evaluating the 'empty shell' hypothesis'. Work, Employment and Society, 18(3), 4I8-505 Pp482

JARVINEN, M. (2000). The Biological Illusion: Constructing Meaning in Qualitative Interviews. Qualitative Inquiry, 6(3), 370-391

KODZ, J., Harper. H., Dench, S., (2002). Work-Life Balance: Beyond the Rhetoric. Institute for Employment Studies, London.

MOORE, K., Griffiths, M., Richardson, H., Adam, A. (2008). Gendered Futures? Women, the ICT Workplace, and Stories of the Future. Gender, Work and Organisation: Special Issue on Time and Gender, I5 (5), p. 523

PANTELI, A., Stack, J, Atkinson, M., Ramsey, H. (1999) The status of women in the UK IT industry: an empirical study. European Journal of Information Systems, 8, 170-182.

PLATMAN, K., Taylor, P. (2004). Workforce Ageing in the New Economy: A Comparative Study of Information Technology Employment. University of Cambridge, Cambridge. http://www.wane.ca/PDF/Platman\&TaylorSummaryReport2 $\underline{004 . p d f}$

QUEENSBERRY (2006). Career anchors and organizational culture: a study of women in the IT workforce, Special Interest Group on Computer Personnel Research Annual Conference Proceedings of the 2006 ACM SIGMIS CPR conference on computer personnel research, p 342 - 344 
TRAUTH, Eileen. (2005), 'Encyclopedia of Gender and Information Technology'. Idea Group, Hershey, PA, USA.

WAGNER, I., Wodak, R., (2006). Performing Success: identifying strategies of self-presentation in women's biographical narratives. Discourse and Society, 17(3), 3854 III.

WEBSTER, J. (2005) Women in IT Professions: Corporate Structures, Masculine Cultures, paper presented to 3rd European Symposium on Gender and ICT: Working for Change, Manchester, UK, I ${ }^{\text {st }}$ February 2005. 


\section{Appendix}

\section{Vignettes of the 'Disappearing' Women}

The subsequent 'disappearing' women's vignettes allow for a more complete picture of the individual rather from the collective group of women. This added dimension of the collected qualitative data offers the reader an insight into the personal lives of our interviewees on both a domestic and working level

Beatrice is a competent 60-65 year old and is married with no children. In 1963 she gained a degree in mathematics and began working at an electrical engineering company where she stayed for almost 30 years until redundancy forced her to leave. Discarded by her employer, then overlooked by would-be employers, by default she became a 'disappearing' woman from the ICT sector. Ironically, for Beatrice, who was over 50, there was no way back into ICT: "they weren't looking for women over 50 for a start, so after a while I gave up looking".

Belinda is a restless $40-45$ year old single woman, who is still looking for her ideal occupation. She actually handed in her resignation on the morning of the interview: "I do like moving around, I have handed my resignation at this job". This current egalitarian attitude towards her fate is far removed from Belinda's career history - 13 years working in the finance sector for a high-street bank. The higher Belinda climbed the corporate ladder the opportunities reduced and she believed "there was a plateau with lots of others at my level with limited access to the board level".

Dee is a self-confident married mother of four in her mid 40 s, who has led what she describes as "a colourful life". Throughout adulthood Dee has encountered recurring health problems affecting both her social and working life, which eventually forced her to rethink her career path, moving from working in the ICT industry to working contently as a self employed bereavement counselor. In this new occupation, she found something more "meaningful and satisfying...it's lives and people that matter", but it had taken the experience of losing a child to realise this.

Cleo is a perceptive 40-45 year old married mother of two, who is currently achieving a work-life and family balance whilst enjoying her career as a lifestyle consultant. This was a radical departure from what was a 'high flying' technical career as a software developer specialising in legacy systems. Cleo acknowledged that becoming a mother had altered others' perceptions of her. The organisation suddenly became 'chilly'. She realised the newly recruited individual who covered her maternity leave was earning $£ 10,000$ more than her. Cleo left shortly after this. She just got up, cleared her desk and walked out of the door after 13 years with the company.

Chrissie is a focused 30-35 year old married mother of two, who is presently training to be a teacher. Chrissie's career path was directed towards working in ICT from the outset. The last ICT role she applied for and got was a senior manager of Research and Development. She knew from the outset that she was not on the same pay scale as her male peers in similar roles. In the six years she worked for this company, she had two maternity leave career breaks. Her workload and hours increased immensely, leaving little precious time for family life. She was finding it increasingly more difficult to 'juggle' a work life.

Carla is a highly motivated, confident, married 50-55 year old, currently enjoying her role as a careers advisor working with students and various schools within a North West University. Carla 'inadvertently' left the ICT industry I 3 years ago after being in ICT from her teens. The 'push' from her dual programming and management role was due to redundancy. Carla describes the shift from ICT as a positive diversion in her career trajectory even though she never intended to 'disappear' from the industry planning to work in ICT until retirement age, but redundancy, 
Gill is a single, self-motivated, confident $45-50$ year old who is currently enjoying life working as a self-employed health therapist after disappearing from the ICT sector. Her working life journey has been quite an amazing one. She spent seven years working overseas, two years in South Africa, a year in Papua New Guinea, a few months in Nigeria, two years in Norway and two years in Sultanate of Oman. Gill's ICT journey then took her in to a large banking organisation working on a smart card electronic cash system project, where she was Vice President of Implementation. Eventually this impacted on her ability to create or join a social network, she comments "I was lonely, I found it very difficult to make friends".

Lydia is an enthusiastic, practical, married 30-35 year old, who cheerfully works as a business advisor for a women's charity organisation. Lydia 'fell into' the ICT sector purely by chance; it was totally unplanned, as was her exit. As an Account Manager the role required traveling away from home throughout the week; it was time consuming and demanding. Her mother became ill and Lydia became her primary career. She found juggling her personal and work life more and more stressful, resulting in her finally succumbing to the pressure and taking a six month career break, after which she never returned to ICT.

Maddy is a disillusioned unemployed woman in her mid 20s, whose ICT career path was 'cut short' due to relocating to the North West of England. 15 months later, Maddy still struggling to find work in the ICT industry. This is not through lack of trying, on average Maddy has attended one interview per week applying for a myriad of ICT roles. It was not unusual for Maddy to be the only female attending interviews; she was never phased by this and went into interviews with her usual gusto, but after being 'knocked back' so many times, she became suspicious that her being a female applying for male dominated roles was a possible barrier to employment. 